\title{
Hyperbaric Oxygen Intervention Modulates Early Brain Injury after Experimental Subarachnoid Hemorrhage in Rats: Possible Involvement of TLR4/NF-K B-Mediated Signaling Pathway
}

\author{
Hao Liu ${ }^{a}$ Ming Yang ${ }^{b}$ Li Pan ${ }^{b}$ Peng Liu ${ }^{b}$ Lianting Maa \\ aSouthern Medical University, 1838 Guangzhou Avenue North, Guangzhou, ${ }^{b}$ Department of Neurosurgery, \\ Wuhan General Hospital of Guangzhou Military Command, Wuhan, People's Republic of China
}

\section{Key Words}

Hyperbaric oxygen • Early brain injury • Inflammatory • Toll-like receptor 4

\begin{abstract}
Background/Aims: Previous studies have proved that the activation of TLR4/NF- $\mathrm{K} B$ signaling pathway is involved in inflammatory processes in early brain injury (EBI) after subarachnoid hemorrhage $(\mathrm{SAH})$. Hyperbaric oxygen ( $\mathrm{HBO}$ ) intervention has successfully been used to treat several animal models of tissue injury via its anti-inflammation property. This study was undertaken to investigate the influence of $\mathrm{HBO}$ administration on the TLR4/NF- $\mathrm{K} B$ signaling pathway in rats at the early stage of SAH. Methods: Male Sprague-Dawley rats $(n=150)$ were randomly divided into 5 groups: the sham, the sham +2.8 atmospheres absolute (ATA) HBO group, the SAH group, the SAH + 2.0ATA HBO group, the SAH + 2.8ATA HBO group. Each group ( $n=30$ ) was randomly subdivided into three subgroups that were examined at the following time points: $24 \mathrm{~h}, 48 \mathrm{~h}$ and $72 \mathrm{~h}$ post-injury. HBO (100\% O2, 2.0ATA or 2.8ATA for 90 mins) was initiated $12 \mathrm{~h}$ after injury. Neurological deficit, brain edema and blood-brain barrier (BBB) permeability were assessed to evaluate the development of EBI. The expressions of TLR4, NF-K B and pro-inflammatory cytokines in the cortical were determined by real time polymerase chain reaction (RT-PCR), western blot, immunohistochemistry, or enzymelinked immunosorbent assay (ELISA). Results: Our study showed that treatment with HBO significantly decreased the expressions of TLR4, NF-K B and the downstream inflammatory agents, such as TNF- $\alpha$, IL-6, IL-1 $\beta$ and ICAM-1, and also improved brain edema, blood-brain barrier permeability and neurologic function. Conclusions: These findings indicate that HBO treatment may result in abatement of the development of EBI after $\mathrm{SAH}$, possibly through suppression of TLR4/NF-K B signaling pathway.
\end{abstract}




\section{Introduction}

Subarachnoid hemorrhage(SAH) is a devastating disease frequently leading to death or neurological deficits in the world [1], the occurrence of cerebral vasospasm after SAH used to be considered as the most important contributor to high rates of mortality and morbidity [2], however, a randomized, blinded clinical trial using an endothelin antagonist, clazosentan, have found that clazosentan does not significantly improve mortality or clinical outcome, even though angiographic vasospasm is reversed $[3,4]$.This result indicates that other pathophysiological factors, which are independent of angiographic vasospasm, can contribute to the outcome of patients. Up to now, there has been a growing body of evidence indicating that the inflammation accompanying SAH may play an important role in devastating neurological outcomes $[2,5,6]$. In addition, the term "early brain injury" has recently been used to describe the mechanisms of acute neurologic deterioration after $\mathrm{SAH}$, including cell death, cerebral edema, and neuronal dysfunction within the first $72 \mathrm{~h}$ of the onset [7]. Great evidences for the purpose of highlighting a strong contribution of inflammation to EBI after SAH has been found in animal and clinical studies $[2,7,8]$, so treatment of inflammation within the first $72 \mathrm{~h}$ has also been considered as a major target in the management of patients surviving cerebral aneurysm rupture.

Toll-like receptors (TLRs) are a family of pattern recognition receptors which can detect microbes and trigger a signaling cascade that culminates in the transcription of pro-inflammatory and immunomodulatory factors involved in innate and adaptive immunity [9]. Of the 13 TLRs identified in mouse, toll-like receptors 4 (TLR4) has been demonstrated to play an important role in initiating the inflammation related to stroke, Alzheimer's disease, Huntington's disease and Parkinson's disease $[10,11]$. A growing number of studies have shown that the activation of the TLR4 and nuclear factor-kappa B (NF- $\kappa$ B) signaling pathway is involved in inflammatory processes in early brain damage after SAH $[12,13]$. It has also been reported that suppression of TLR4/NF- $\kappa$ B signaling pathway can down-regulate the gene expression of many inflammatory mediators, such as tumor necrosis factor- $\alpha$ (TNF- $\alpha$ ), interleukin-6 (IL-6), interleukin-1 $\beta$ (IL$1 \beta$ ), intercellular adhesion molecule-1 (ICAM-1), improve neurologic results and alleviate brain injury after SAH [14-16]. Therefore, TLR4/NF- $\mathrm{B}$ signaling pathway may be a therapeutic target for EBI after SAH.

AS a nondrug and noninvasive treatment, hyperbaric oxygen (HBO) has been widely used in clinical practice for many diseases and has led to satisfactory outcomes, especially in the areas of acute carbon monoxide poisoning, cerebral ischemia, decompression sickness [17-19]. Even though investigators have demonstrated that $\mathrm{HBO}$ can be used as an adjunct treatment of SAH to counter cerebral vasospasm because of its potent anti-inflammatory and anti-oxidant properties $[20,21]$, the evidence of physiologic and molecular mechanisms and efficacy of HBO therapy in reducing inflammatory cytokines in the early brain injury period after SAH is still limited.

Recently, a series of studies has shown that, by interfering with the TLR/NF- $\mathrm{K}$ B signaling pathway, HBO therapy can attenuate inflammation and exert a protective effect in experimental animal models of spinal cord injury (SCI) and multiple organ failures [22-24]. These provide a brilliant prospect for the further study of HBO on treatment of EBI and its anti-inflammation mechanism after SAH. The present study attempted to provide a novel mechanism that HBO could inhibit the activation of TLR4 induced by SAH and suppress TLR4/NF- $\kappa$ B signaling pathway.

\section{Materials and Methods}

\section{Animal preparation and study design}

Male Sprague-Dawley (SD) rats weighing between $240 \mathrm{~g}$ and $290 \mathrm{~g}$ were purchased from Experimental Animal Center of Hubei Province, Wuhan, China. All study procedures were approved by Wuhan General Hospital of Guangzhou Military Command and in accordance with the guidelines of the National Institutes of Health on the care and use of laboratory animals. All rats had free access to food and water and were kept at the same environmental temperature, humidity with a $12 \mathrm{~h}$ light-dark cycle for at least 1 week. A total of 150 rats were randomly assigned to 5 groups ( $\mathrm{n}=30$ for each group): (1) the sham (SH) group; (2) the $\mathrm{SH}+2.8$ 


\section{Cellular Physiology Cell Physiol Biochem 2016;38:2323-2336 \\ \begin{tabular}{ll|l} 
DOI: 10.1159/000445586 & $\begin{array}{l}\text { O 2016 The Author(s). Published by S. Karger AG, Basel } \\
\text { www.karger.com/cpb }\end{array}$ \\
\cline { 2 - 3 }
\end{tabular} \\ Liu et al.: Possible Mechanisms of HBO Intervention Brain Injury}

atmospheres absolute (ATA) HBO group; (3) the SAH group; (4) the SAH + 2.0ATA HBO group; (5) the SAH $+2.8 \mathrm{ATA}$ HBO group. 15 of the rats in each group were subdivided into three subgroups ( $\mathrm{n}=5$ per group) corresponding to the following post-operative time points: $24 \mathrm{~h}, 48 \mathrm{~h}$ and $72 \mathrm{~h}$, they were decapitated to obtain brain tissue samples for the biochemical analyses. $48 \mathrm{~h}$ after SAH induction, 5 of the left rats in each group were decapitated for Evans blue (EB) assay, 5 were decapitated for brain edema evaluation, and 5 were given the fixative perfusion for histological preparation and analysis. After flushing $\mathrm{CO}_{2}$ from a small hyperbaric chamber (Hongyuan Oxygen Industry, Yantai, China) with $100 \% \mathrm{O}_{2}$, rats in the SH + 2.8ATA HBO and $\mathrm{SAH}+2.8 \mathrm{ATA} \mathrm{HBO}$ groups were placed inside for a $90 \mathrm{~min}$ exposure to $\mathrm{HBO}\left(100 \% \mathrm{O}_{2}\right)$ at 2.8ATA. The chamber pressure was increased to 2.8ATA in $15 \mathrm{~min}$ and then gradually decreased to normal pressure $(20 \%$ 02) in 10 mins at the end of the session. In the SAH+2.0ATA HBO group, the animals were treated with 2.0ATA HBO using the same method. Animals in each of these three groups received five sessions of HBO treatment in total, which started $12 \mathrm{~h}$ after SAH induction and was given once daily in the first day and twice on the second and third day. At the planed time point, the animals were anesthetized and decapitated for different assays. In each group, five rats were manipulated for detecting brain water content, and five were used for blood-brain barrier (BBB) permeability, and fifteen were taken for molecular biological and biochemical experiments, and another five rats were used for immunohistochemistry studies. The time of sacrifice was determined according to the different parameters measured: measurement of brain edema and BBB permeability: $48 \mathrm{~h}$ after SAH; Real time polymerase chain reaction (RT-PCR) analysis: $48 \mathrm{~h}$ after SAH; Enzyme-linked immunosorbent assay (ELISA): $48 \mathrm{~h}$ after SAH; Western blot analysis: $24 \mathrm{~h}, 48 \mathrm{~h}$ and $72 \mathrm{~h}$ after SAH; Immunohistochemistry: $48 \mathrm{~h}$ after SAH.

\section{Induction of experimental SAH and sham operation}

The experimental SAH model was established according to the prechiasmatic injection method described in previous study [25]. Briefly, rats were weighed and anaesthetized through intraperitoneal injection of $10 \%$ chloral hydrate ( $3.5 \mathrm{ml} / \mathrm{kg}$, I. p.), and then the rats were positioned prone in a stereotactic apparatus. A midline scalp incision was made and a $1 \mathrm{~mm}$ hole was drilled $7.5 \mathrm{~mm}$ anterior to the bregma in the midline without damaging the dura. A27 gauge spinal needle was advanced $11 \mathrm{~mm}$ into the prechiasmatic cistern through this burr hole at an angle of $30 \mathrm{E}$ caudally. The amount of $0.3 \mathrm{ml}$ non-heparinized fresh autologous blood from the femoral artery was slowly injected into the prechiasmatic cistern over $20 \mathrm{~s}$ with a syringe pump under aseptic technique. Animals in sham group were injected with an equal volume of sterile saline in the same manner. The burr hole was sealed with bone wax, and the incision was surgically sutured. When the operation were done, $1 \mathrm{ml}$ of $0.9 \% \mathrm{NaCl}$ solution was injected subcutaneously to prevent dehydration and then the rats were kept in a $30 \mathrm{E}$ head-down position. After all the procedures, the animals were then returned to their cages, heart rate and blood pressure were monitored, body temperature was maintained with a heating pad.

\section{Grading system for $S A H$}

The severity of SAH has closely relation to the amount of blood in brain, in order to confirm that the severity of SAH is similar in all the SAH groups, the grading system depending on the amount of subarachnoid blood clot was established in this study according to the method described in previous study [26]. In brief, the brains of animals ( $\mathrm{n}=5$ per group) were removed rapidly at $24 \mathrm{~h}$ after operation, pictures of the base of the brain were taken, the basal cistern was divided into six segments. Each segment was allotted a grade from 0 to 3 as follows-Grade 0: no subarachnoid blood; Grade 1: minimal subarachnoid blood; Grade 2: moderate blood clot with recognizable arteries; Grade 3: blood clot obliterating all arteries within the segment. The animals received a total score ranging from 0 to 18 after adding the scores from all six segments.

\section{Neurologic scoring}

Neurological functions were evaluated at $24 \mathrm{~h}, 48 \mathrm{~h}$ and $72 \mathrm{~h}$ after SAH in double-blind model using the scoring system to record appetite, activity and neurological deficits of experimental animals as previous described [27]. The test consists of three segments that can be scored 0-2 (Table 1). The maximum score is 6 and the minimum score is 0 . Lower scores indicate greater function. There are five animals in each group for neurologic scoring study at the planned time point.

\section{KARGER}




\section{Cellular Physiology Cell Physiol Biochem 2016;38:2323-2336 and Biochemistry Published online: May 23, $2016 \quad \begin{aligned} & \text { DOI: 10.1159/000445586 } 2016 \text { The Author(s). Published by S. Karger AG, Basel } \\ & \text { www.karger.com/cpb }\end{aligned}$ \\ Liu et al.: Possible Mechanisms of HBO Intervention Brain Injury}

Table 1. Behavior scores

\begin{tabular}{llc}
\hline Category & \multicolumn{1}{c}{ Behavior } & Score \\
\hline Appetite & Finish meal & 0 \\
& Left meal unfinished & 1 \\
& Scarcely ate & 2 \\
Activity & Walk and reach at least three & 0 \\
& Corners of the cage & \\
& Walk with some stimulation & 1 \\
& Almost always lying down & 2 \\
Deficits & No deficits & 0 \\
& Unstable walk & 1 \\
& Impossible to walk & 2 \\
\hline
\end{tabular}

Brain water content

Brain edema was calculated according to the following formula as previously described [14-16], brain water $=[($ wet weight-dry weight $) /$ wet weight $] \times 100 \%$. Briefly, $48 \mathrm{~h}$ after operation, rats were anesthetized and decapitated, and brains were harvested and immediately separated to hemispheres, cerebellum, and brain stem, and then weighted as wet weight. Brain specimens were dried in an oven at $110^{\circ} \mathrm{C}$ for $72 \mathrm{~h}$ and then reweighed to obtain dry weight. There are five animals in each group for brain edema study.

\section{Blood-brain barrier permeability}

Blood-brain barrier (BBB) permeability was determined by Evans blue (EB) extravasation at $48 \mathrm{~h}$ after SAH. In brief, EB dye $(2 \%, 4 \mathrm{~mL} / \mathrm{kg})$ was injected in 2 min into the left femoral vein at a dose of $2 \mathrm{ml} / \mathrm{kg}$ and allowed to circulate for $1 \mathrm{~h}$. Rats were anesthetized and perfused transcardially using saline to remove intravascular EB dye. After decapitated, the entire brain of each animal was removed and homogenized in physiological phosphate buffered saline. Trichloroacetic acid was then added to precipitate the protein, and the samples were cooled and centrifuged. The resulting supernatant was measured for absorbance of EB at $620 \mathrm{~nm}$ by using a spectrophotometer.

\section{Quantitative real-time polymerase chain reaction}

The messenger RNA (mRNA) levels of inflammatory mediators were determined by quantitative RTPCR analysis. Total RNA was extracted from brain tissue using a Trizol reagent (Invitrogen, Shanghai, China) following the manufacturer's recommendations. RNA was reverse-transcribed to obtain cDNA and amplified according to previous methods [14, 15], and RT-PCR analysis was performed using the Ex TaqTM, DL2000 DNA Marker (TAKARA Biotechnology, Dalian, China) and SYBR Green/Flourescein qPCR Master Mix (2X) kit (Fermentas, Shanghai, China) according to the manufacturer's instruction. Glyceraldehyde 3-phosphatedehydrogenase (GAPDH) was served as an endogenous control. The PCR primers sequences were designed by the Genscript Biological Technology Company (Nanjing, China) according to the GAPDH, TLR4 and NF- $\kappa$ $\mathrm{B}$ (p65) gene sequences reported in GenBank. The following primer sets were used: GAPDH (253bp), 5'-ACA GCA ACA GGG TGG TGGAC-3' (forward) and 5'-TTT GAG GGT GCA GCG AACTT-3' (reverse); TLR4 (239bp), 5'-CCA GAG CCG TTG GTG TATCT-3' (forward) and 5'-TCA AGG CTT TTC CAT CCAAC-3' (reverse); and NFB p65 (251bp), 5'- GGC AGC ACT CCT TAT CAACC -3' (forward) and 5'-GAG GTG TCG TCC CAT CGTAG -3' (reverse). The cycling conditions were as follows: $50^{\circ} \mathrm{C}$ for $2 \mathrm{~min}, 95^{\circ} \mathrm{C}$ for $10 \mathrm{~min}$ and 40 cycles of $95^{\circ} \mathrm{C}$ for $30 \mathrm{sec}$ and $60^{\circ} \mathrm{C}$ for $30 \mathrm{sec}$. Melting curve, which was measured immediately after amplification, showed a single product peak, indicating good product specificity. All samples were analyzed in triplicate. Data were analyzed using the Line-Gene software. The mRNA expression levels were calculated with the $2^{-\Delta \Delta \mathrm{CT}}$ method and normalized by quantity of GAPDH mRNA.

\section{Enzyme-linked immunosorbent assay (ELISA)}

IL-1 $\beta$, IL- 6 and TNF- $\alpha$ levels of animals were measured by ELISA at different time points after SAH or saline administration. The frozen cortex tissue of rats was mechanically homogenized and centrifuged at $12,000 \mathrm{rpm}$ for $10 \mathrm{~min}$ at $4^{\circ} \mathrm{C}$. The levels of inflammatory cytokines of the brain tissue homogenates were quantified using specific ELISA kits for rats according to the manufacturers' instructions (Elabscience Biotechnology, Wuhan, China). The inflammatory mediators were expressed as pictogram per milligram protein. 


\section{Cellular Physiology Cell Physiol Biochem 2016;38:2323-2336 and Biochemistry Published online: May 23, $2016 \quad \begin{aligned} & \text { DOI: 10.1159/000445586 } 2016 \text { The Author(s). Published by S. Karger AG, Basel } \\ & \text { www.karger.com/cpb }\end{aligned}$}

Liu et al.: Possible Mechanisms of HBO Intervention Brain Injury

Western blot analysis

The frozen brain samples from the ipsilateral basal cortex were homogenized with RIPA lysis buffer (Beyotime, Inc., Shanghai, China) and then centrifuged at $12,000 \times \mathrm{g}$ for $20 \mathrm{~min}$ at $4^{\circ} \mathrm{C}$. The protein concentration was estimated using the BCA Protein Assay Kit (Beyotime, Inc., Shanghai, China). Equal amounts of protein samples ( $50 \mu \mathrm{g}$ per lane) in the supernatant were separated by sodium dodecyl sulfatepolyacrylamide gel electrophoresis (SDS-PAGE) and electro transferred to polyvinylidene-difluoride (PVDF) membrane. The membranes were then nurtured in a blocking buffer, $5 \%$ defatted milk in Tris-buffered saline containing Tween 20 (TBST), for $2 \mathrm{~h}$ at room temperature and then incubated overnight at $4^{\circ} \mathrm{C}$ with primary antibodies for TLR4, NF- $\mathrm{K}$ B and ICAM-1 at the dilutions of 1:500, 1:3000, and 1:300, respectively. GAPDH diluted at 1:6000 was served as a loading control. After being washed with TBST, the incubated membranes were then treated with secondary antibody conjugated with horseradish peroxidase (HRP) diluted at 1:50000 in TBST at room temperature for $2 \mathrm{~h}$. After the membranes were washed, the blotted protein bands were visualized by enhanced chemiluminescence (ECL) detection kit (Thermo Fisher Scientific, Waltham, MA, USA) and then exposed to X-ray film. Optical density of the resulting bands was quantified by optical density methods using Glyko Bandscan software (Glyko, Novato, CA, USA). The expression levels of TLR4, $\mathrm{NF}-\kappa \mathrm{B}$ and ICAM-1 were normalized to GAPDH for at least three times.

Perfusion-fixation and immunohistochemistry

$48 \mathrm{~h}$ after SAH or saline injection, the rats were reanesthetized as described previously; perfusionfixation was then performed. The thorax of rat was opened, with a cannula placed in the left ventricle, and the wall of the right atrium was opened. Then the animal was perfused through the left cardiac ventricle with $100 \mathrm{ml}$ of $0.9 \%$ normal saline solutions followed by $500 \mathrm{ml}$ of $4 \%$ buffered paraformaldehyde. The brains were harvested immediately and stored in the same fixative solution overnight and then embedded in paraffin for further analysis. Brain sections were hydrated in graded concentrations of ethanol and placed

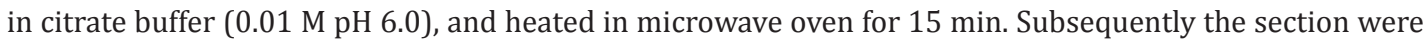
treated with $3 \%$ hydrogen peroxide for $15 \mathrm{mins}$ at room temperature to block endogenous peroxidase activity, followed by a brief rinse in distilled water and a 9 min wash in PBS. Then sections were incubated with primary antibodies overnight at $4^{\circ} \mathrm{C}$, followed by a $9 \mathrm{~min}$ wash in PBS. The following antibodies (Santa Cruz Biotechnology Inc., CA, USA) were applied: rat anti-TLR4, rat anti-NF- $\kappa$ B (P65) at a concentration 1:100 each. Sections incubated in the absence of primary antibody were used as negative controls. On the following day, the sections were incubated with horseradish peroxidase (HRP)-conjugated IgG for 30 min at room temperature. DAB was used as chromogen and microscopy of the immune histochemically stained tissue sections was performed by an experienced pathologist who was unaware of the experimental condition. All numbers of positive cells in each section were counted in 10 microscope fields (400x), and the mean percentage per visual field was calculated.

\section{Statistic analysis}

All data are presented as means \pm standard error of the mean (SEM) and SPSS 12.0 was used for statistical analysis of the results. All data are subjected to one-way analysis of variance (ANOVA) followed by the LSD and Dunnett's post-hoc test for multiple comparisons. Difference, at a probability value less than 0.05 , was considered significant.

\section{Results}

General observation, mortality and severity of SAH

No significant statistical differences in the recorded physiological parameters, including body weight, blood pressure and temperature, were detected in any of the experimental groups. Total 150 rats were used in this study. Animals died in the course of anesthesia or blood injection were excluded from further analysis. Within $72 \mathrm{~h}$, no animals died in the $\mathrm{SH}$ group and $\mathrm{SH}+$ 2.8ATA HBO group. The mortality after surgery was $28.6 \%$ (8 of 28) in the SAH group, $26.9 \%$ (7 of 26) in the SAH + 2.0ATA HBO group, and 22.2\% (6 of 27) in the SAH + 2.8ATA HBO group. There was no significant difference among these groups in mortality. 
Fig. 1. The scores for severity in all the SAH groups were showed, there was no significant difference in statistical analysis between these groups, it indicated that the degree of SAH in all the SAH groups was comparable. \# $\mathrm{P}>0.05$ versus the $\mathrm{SAH}$ group, \& $\mathrm{P}>0.05$ versus the SAH + 2.0ATA HBO group.

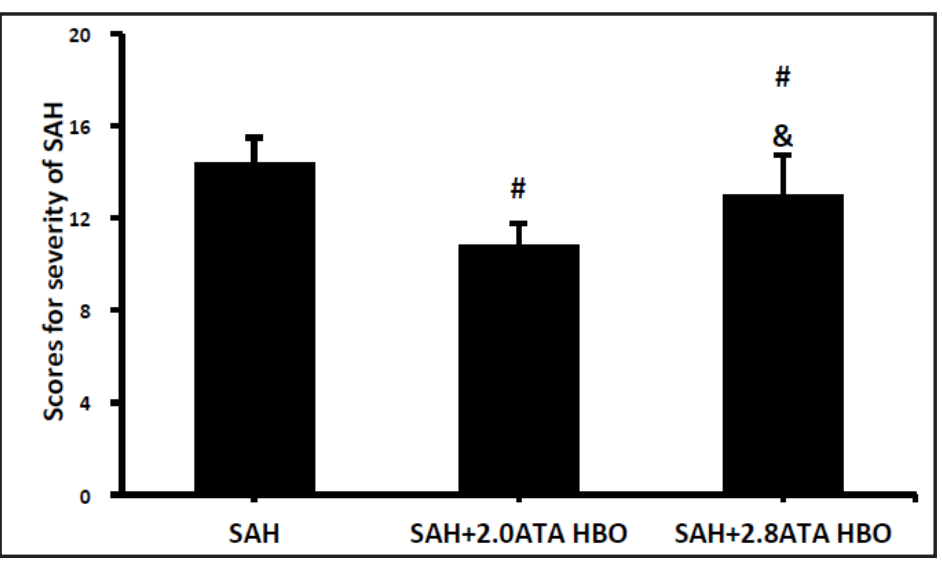

The grading system depending on the amount of subarachnoid blood clot showed that animals in the SH and the SH + 2.8ATA HBO groups did not have any hemorrhage and thus received a total score of 0 . The scores of rats in all the SAH groups were showed in Fig. 1, there was no significant difference in statistical analysis between these groups, it indicated that the degree of SAH in all the SAH groups was comparable.

Effects of HBO on EBI after SAH

In order to check the effects of HBO treatment on neurological deficit after SAH in each group, neurological scores were evaluated at $24 \mathrm{~h}, 48 \mathrm{~h}$ and $72 \mathrm{~h}$ after operation. Neurologic scores in the SAH group were significantly higher than that in the sham group at different time points ( $\mathrm{P}<0.01$, Fig. $2 \mathrm{~A}$ ), while Treatment with HBO both at 2.8 ATA and 2.0 ATA dramatically lowered neurological scores compared with the SAH group at $24 \mathrm{~h}, 48 \mathrm{~h}$ and $72 \mathrm{~h}(\mathrm{P}<0.05$, Fig. $2 \mathrm{~A})$, even though the point level calculated in these two groups was significantly higher than the control value of sham group $(\mathrm{P}<0.05$, Fig. $2 \mathrm{~A})$.

A significant increase in water content was detected in the bilateral cerebral hemispheres at $48 \mathrm{~h}$ after $\mathrm{SAH}(\mathrm{P}<0.01$, Fig. 2B). However, no difference in water content in cerebellum or brain stem was noted ( $\mathrm{P}>0.05$, Fig. $2 \mathrm{~B})$. The mean value of brain water content in cerebral was evidently decreased by HBO administration of both 2.0 ATA and 2.8 ATA as compared with SAH group ( $\mathrm{P}<0.05$, Fig. 2B).

As compared to animals of the SH group, rats in SAH group demonstrated a significant increase in the amount of Evans blue dye extravasation at $48 \mathrm{~h}(\mathrm{P}<0.01, \mathrm{Fig} .2 \mathrm{C})$ and the levels of extravasated dye were significantly reduced by 2.0ATA and 2.8ATA HBO treatment compared to SAH group ( $<<0.05$, Fig. 2 C).

There was no significant difference in any measured parameters between the $\mathrm{SH}$ and the $\mathrm{SH}$ $+2.8 \mathrm{ATA}$ HBO groups ( $\mathrm{P}>0.05$, Fig. 2A-2C). Although there was no significant difference in brain water content and neurologic score between the SAH + 2.0 ATA HBO and the SAH + 2.8ATA HBO groups ( $\mathrm{P}>0.05$, Fig. 2A, 2B), high dose of $\mathrm{HBO}$ administration has led to amelioration in $\mathrm{BBB}$ permeability with statistical differences at $48 \mathrm{~h}$ after $\mathrm{SAH}(\mathrm{P}<0.05$, Fig. $2 \mathrm{C})$, indicating that there may be a reduced $\mathrm{BBB}$ opening in response to the high dosage of $\mathrm{HBO}$ treatment.

\section{Effect of HBO on expression of TLR4, NF- $\kappa$ B and ICAM-1}

To evaluate the effects of HBO on the inflammation after SAH, we assessed the mRNA and protein levels of TLR-4 and NF- $\kappa$ B. Western blot showed that TLR- 4 and NF- $\kappa$ B were expressed at a low level in cortex in the SH and SH + 2.8ATA groups (Fig. 3D, 3E). The protein expression did not differ significantly between these two groups ( $P>0.05$, Fig. 3D, 3E). However, the protein levels of TLR-4 and NF- $\kappa$ B were increased significantly in rats subjected to SAH (P $<0.01$, Fig. 3D, $3 \mathrm{E}$ ), moreover, TLR- 4 and NF- $\kappa$ B protein expression reached peak values at $48 \mathrm{~h}$ after SAH (Fig. 3D, 3E). As shown in Fig. 3A-3C, treatment with HBO decreased these cytokine levels after SAH at $24 \mathrm{~h}, 48 \mathrm{~h}$ and $72 \mathrm{~h}$ when compared with those of SAH group, indicating that the treatment of HBO may result in downregulation of the TLR signaling pathway at protein level. 
Fig. 2. Effects of HBO on neurologic scores $(A)$, brain water content (B), and BBB permeability (C) in rats after $\mathrm{SAH}$. There was no difference in brain water content, BBB permeability, and neurologic scores between the $\mathrm{SH}$ and the $\mathrm{SH}$ +2.8 ATA HBO groups. Compared with the SH group, SAH led to a significant increase in the neurologic dysfunction, brain water content and EB extravasation. HBO (2.0 ATA and 2.8 ATA) treatment after SAH significantly reduced brain edema, BBB dysfunction, and neurologic deterioration compared with that of the SAH group. No difference of brain edema and neurologic scores was detected between the dosages of 2.0 ATA and 2.8 ATA HBO treatment groups. However, high dose of HBO administration have led to amelioration in BBB permeability with statistical differences at $48 \mathrm{~h}$ after SAH. Data are shown as mean \pm SEM. Statistical significance was analyzed by oneway ANOVA. \# P $>0.05$ versus the $\mathrm{SH}$ group, $* \mathrm{P}<0.01$ versus the SH group, \#\# $\mathrm{P}<0.05$ versus the SAH group, \& $\mathrm{P}>0.05$ versus the $\mathrm{SAH}+2.0$ ATA HBO group, ${ }^{* * *} \mathrm{P}<$ 0.05 versus the $\mathrm{SAH}+2.0 \mathrm{ATA}$ HBO group.

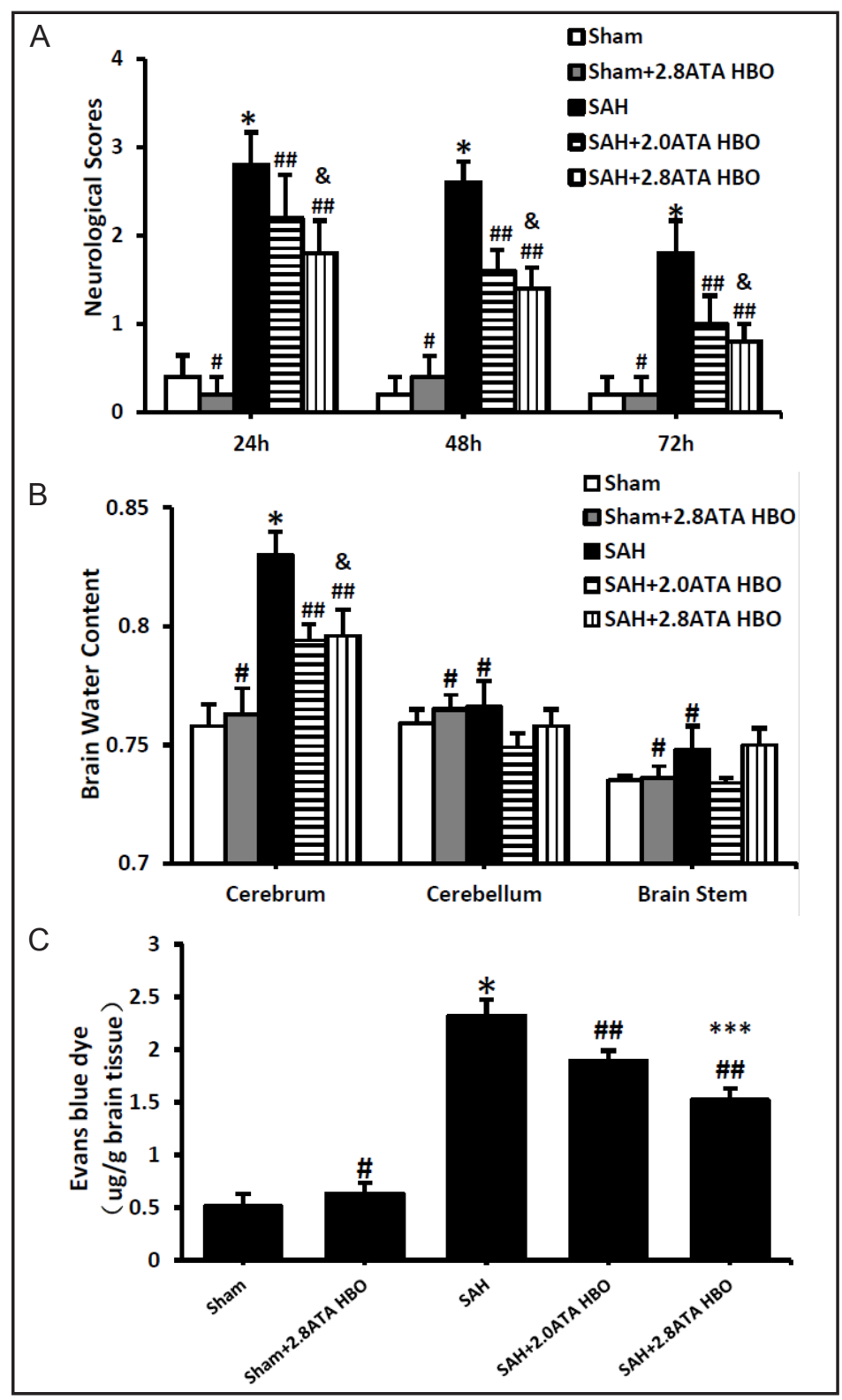

As shown in Fig. 3F, the mRNA levels of TLR-4 and NF- $\mathrm{B}$ were significantly elevated after $\mathrm{SAH}$ when compared with the sham group $(\mathrm{P}<0.01)$. Treatment with HBO led to a significant decrease in the mRNA level of TLR- 4 and NF- $\kappa$ B $(\mathrm{P}<0.05)$ at $48 \mathrm{~h}$ after SAH. These results suggested that HBO may inhibit the induction of mediators at mRNA level. Although these data showed that the average mRNA and protein levels were still higher in dosage of 2.0 ATA HBO administration, there was no significant statistical difference in any measured parameters between the $\mathrm{SAH}+2.0 \mathrm{ATA} \mathrm{HBO}$ and $\mathrm{SAH}+2.8$ ATA HBO treatment groups $(\mathrm{P}>0.05)$.

The activity of ICAM-1 in the brain sample was also detected by Western blot at $48 \mathrm{~h}$ after SAH. The representative picture was shown in Fig. 4. ICAM-1 activity was inhibited by HBO administration groups $(\mathrm{P}<0.05)$, and 2.8ATA HBO administration could not inhibit the activity of ICAM-1 obviously by comparison with that of the SAH + 2.0ATA HBO group $(\mathrm{P}>0.05)$.

Effect of HBO on pro-inflammatory cytokine expression

In order to test the effect of $\mathrm{HBO}$ on the inflammation after $\mathrm{SAH}$, pro-inflammatory cytokines of TNF- $\alpha$, IL- $1 \beta$ and IL- 6 were measured by ELISA at $48 \mathrm{~h}$ after the operation in all experimental 


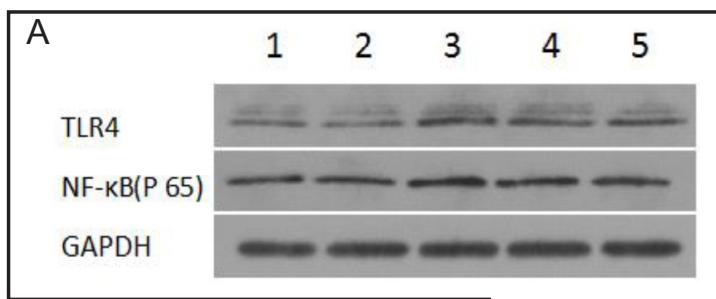

Fig. 3. Effects of HBO treatment on the protein levels of TLR-4 and $\mathrm{NF}-\kappa \mathrm{B}$ in cortex sample at $24 \mathrm{~h}, 48$ $\mathrm{h}$ and $72 \mathrm{~h}$ (A-E) and mRNA levels at $48 \mathrm{~h}(\mathrm{~F})$ after $\mathrm{SAH}$ in all experimental groups. Expression levels of protein and mRNA are normalized with GAPDH. There was no significant difference between the $\mathrm{SH}$ and $\mathrm{SH}+2.8 \mathrm{ATA}$ groups. It shows that the protein and mRNA levels of TLR-4 and NF- $\kappa$ B in the $\mathrm{SAH}$ groups were significant higher than those in the sham group. However, HBO treatment, including dosages of 2.0 ATA and 2.8 ATA HBO, could evidently reduce TLR-4 and NF- $\kappa$ B concentration in both protein and mRNA levels compared with SAH group. Although high dose of HBO (2.8 ATA) have led to marked amelioration in the upregulation of TLR-4 and NF- $\kappa$ B, there was no statistical difference in measured parameters between the SAH + 2.0 ATA HBO and the SAH + 2.8ATA HBO groups. Data are shown as mean \pm SEM. Statistical significance was analyzed by one-way ANOVA followed by LSD and Dunnett's post-hoc. \# $\mathrm{P}>0.05$ versus the $\mathrm{SH}$ group, ${ }^{*} \mathrm{P}$ $<0.01$ versus the SH group, \#\# P $<0.05$ versus the $\mathrm{SAH}$ group, \& $\mathrm{P}>$ 0.05 versus the $\mathrm{SAH}+2.0 \mathrm{ATA} \mathrm{HBO}$ group. $\mathrm{F}$
C

B
TLR4
NF-KB(P 65)
GAPDH

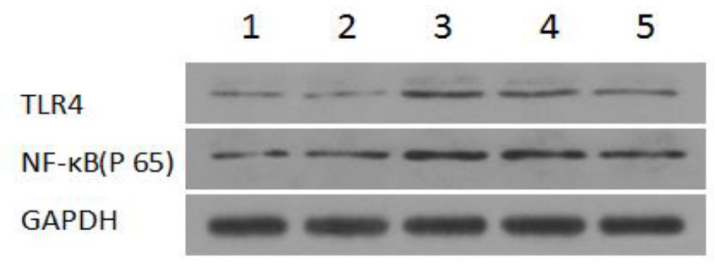

$1:$ SH; $2:$ SH + 2.8ATA; $3:$ SAH; $4:$ SAH + 2.0ATA; $5:$ SAH + 2.8ATA

D

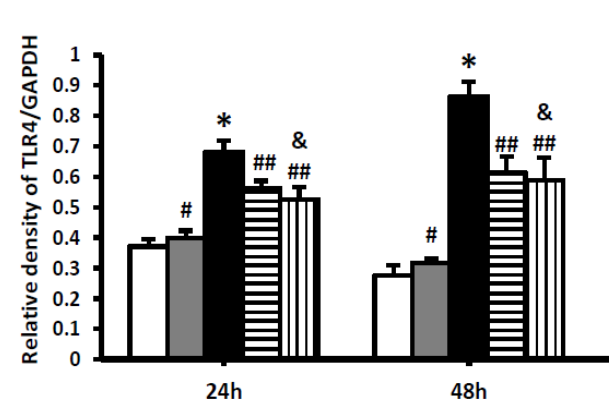

E

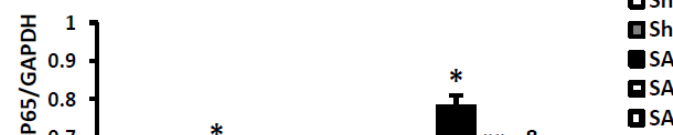

DSham

口Sham+2.8ATA HBO ISAH 口SAH+2.0ATA HBO 口SAH+2.8ATA HBO

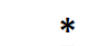
* 8

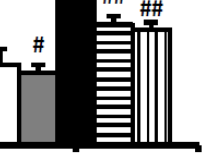

$72 \mathrm{~h}$ DSham Sham+2.8ATA HBO SAH +2.0ATA HBO (24h $48 \mathrm{~h}$ $72 \mathrm{~h}$

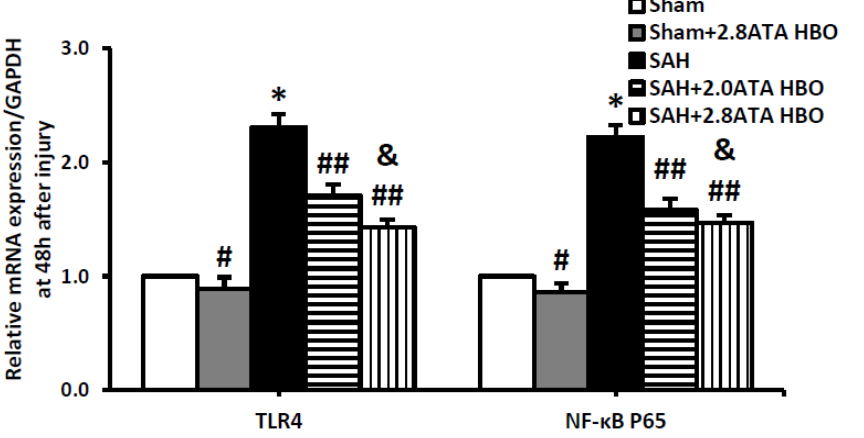

groups. The concentrations of mediators were present at low levels in the sham groups, and the expression of TNF- $\alpha$, IL- $1 \beta$ and IL- 6 did not differ significantly between the sham and sham +2.8 ATA HBO groups ( $\mathrm{P}>0.05$, Fig. 5). The levels of the three pro-inflammatory cytokines in cortical were dramatically increased after SAH at $48 \mathrm{~h}(\mathrm{P}<0.01$, Fig. 5). However, the expression of mediators in rats subjected to SAH was attenuated significantly after treatment of HBO both at the dosages of 2.0 ATA and 2.8ATA ( $<<0.05$, Fig. 5). The dosage of 2.8ATA HBO administration to 
Fig. 4. Representative Western blots and quantitative analysis of ICAM-1 in cortex sample at $48 \mathrm{~h}$ after $\mathrm{SAH}$ in all experimental groups. GAPDH was used as an internal control. It shows that the expression of ICAM-1 in the SAH group was increased significantly than that in the sham group. The HBO treatment markedly reduced the level of ICAM-1. No significant difference of ICAM-1 was detected between the dosages of 2.0 ATA and 2.8 ATA in the brain samples after SAH at 48 h. Data are shown as mean \pm SEM. Statistical significance was analyzed by one-way ANOVA. \# P > 0.05 versus the $\mathrm{SH}$ group, ${ }^{*} \mathrm{P}<0.01$ versus the $\mathrm{SH}$ group, \#\# $\mathrm{P}<0.05$ versus the SAH group, \& P >0.05 versus the SAH + 2.0ATA HBO group.
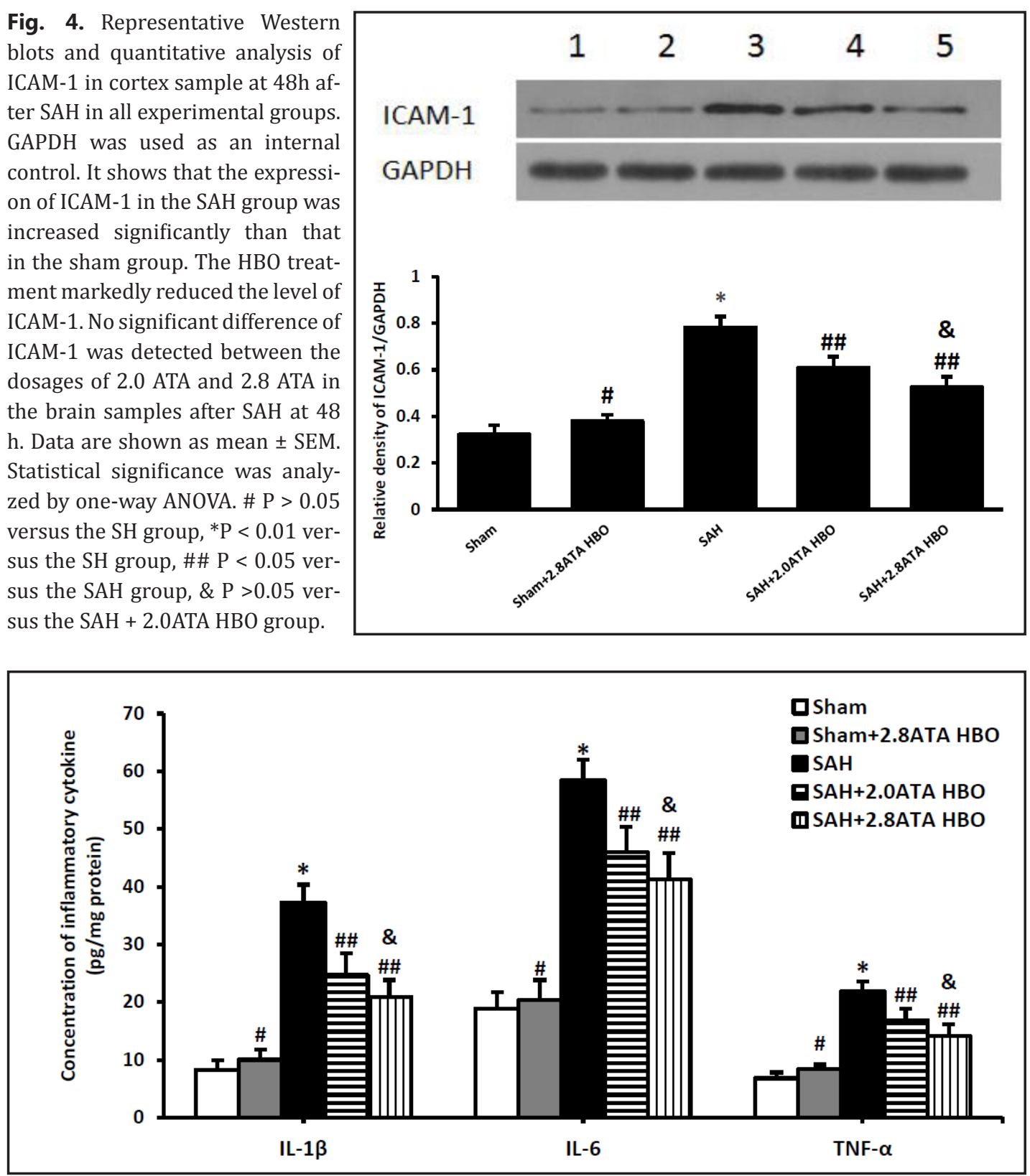

Fig. 5. Changes of inflammatory mediators in the injured brains as determined by ELISA at $48 \mathrm{~h}$ in all experimental groups. SAH could induce the significantly increased concentrations of TNF-a, IL-1 $\beta$ and IL-6 in the rat brain after SAH. In the HBO treatment groups, including the dosages of 2.0 ATA and 2.8 ATA, the cortical concentrations of TNF-a, IL-1 $\beta$ and IL- 6 were markedly downregulated following SAH. No statistical difference of concentrations of pro-inflammatory mediators was detected between the dosages of 2.0 ATA and 2.8 ATA HBO groups. Data are shown as mean \pm SEM. Statistical significance was analyzed by one-way ANOVA. \# $\mathrm{P}>0.05$ versus the SH group, $* \mathrm{P}<0.01$ versus the SH group, \#\# $\mathrm{P}<0.05$ versus the SAH group, \& $\mathrm{P}>0.05$ versus the $\mathrm{SAH}+2.0 \mathrm{ATA} \mathrm{HBO}$ group.

rats of SAH could not suppress the expression of TNF- $\alpha$, IL- $1 \beta$ and IL- 6 obviously than those in the SAH + 2.0ATA HBO group ( $>$ > 0.05, Fig. 5).

Immunohistochemical study on brain samples

Immunohistochemistry was subsequently performed to detect the localization of TLR4 and NF- $\kappa$ B P65 and assess the effect of HBO on the expression of cytokines at $48 \mathrm{~h}$ after surgery. 
Fig. 6. Immunohistochemical study of TLR4 and NF-K B on brain samples at $48 \mathrm{~h}$ after injury. ( $A$ and $B$ ) shows the representative photomicrographs of these proteins in each group (400x, scale bars, 100 um). TLR-4 and NF-K $B$ positive cells, stained brown. (C) shows the quantification of positive cells in each group. Positive cells of TLR-4 and NF-k B were evidently reduced by HBO administration. However, 2.8ATA HBO administration could not significantly reduce the number of positive cells compared with 2.0ATA HBO administration. Data are shown as mean \pm SEM. Statistical significance was analyzed by one-way ANOVA. \# P > 0.05 versus the SH group, ${ }^{*} \mathrm{P}<0.01$ versus the SH group, \#\# $\mathrm{P}<0.05$ versus the SAH group, \& $\mathrm{P}>0.05$ versus the SAH + 2.0ATA HBO group.

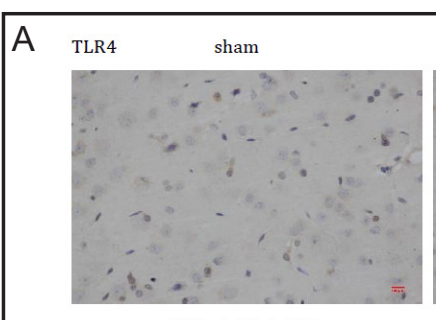

$\mathrm{SAH}+2.0 \mathrm{ATA}$ HBO
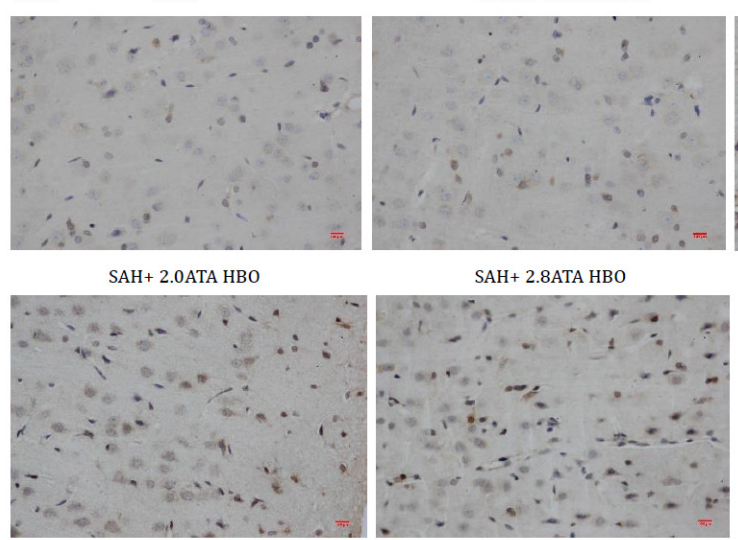

$\mathrm{SAH}+2.8 \mathrm{ATA} \mathrm{HBO}$

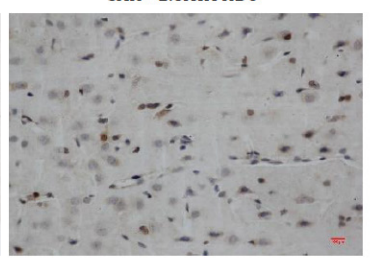

sham+ 2.8ATA HBO
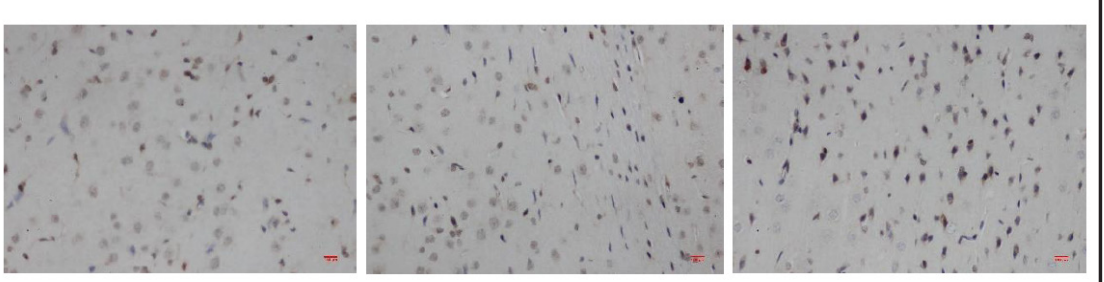

$\mathrm{SAH}+2.0 \mathrm{ATA} \mathrm{HBO}$

$\mathrm{SAH}+2.8 \mathrm{ATA} H \mathrm{HBO}$
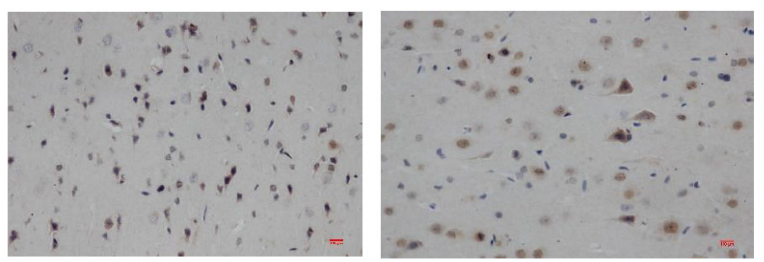

C

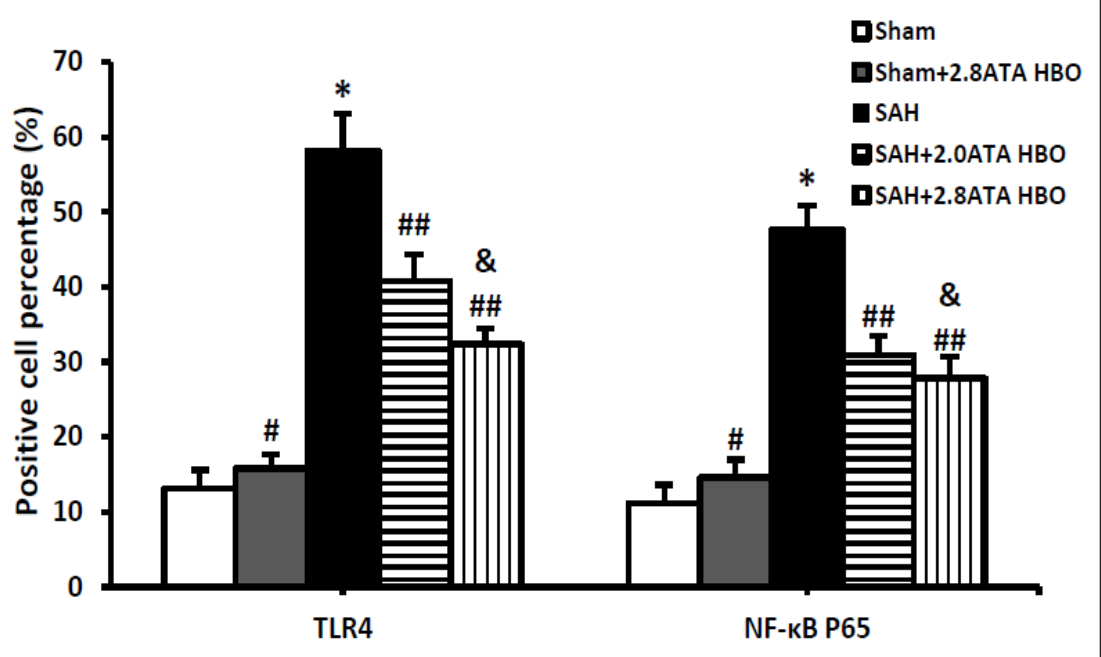

The results of the immunohistochemistry experiment revealed a significant increase of TLR4 and NF- $\kappa$ B positive cells in the cortex of the SAH group ( $\mathrm{P}<0.01$, Fig. $6 \mathrm{C})$. These proteins' immunoreactivity was mainly observed in neurons and a little in glial cells (Fig. 6A, 6B). Similar to the Western blot, HBO administration (both 2.0 ATA and 2.8 ATA) reduced the number of TLR4 and NF- $\kappa$ B positive cells remarkably in the cortical of rats at $48 \mathrm{~h}$ after blood injection $(\mathrm{P}<0.05$, 


\section{Cellular Physiology Cell Physiol Biochem 2016;38:2323-2336 \\ and Biochemistry Published online: May 23, $2016 \quad \begin{aligned} & \text { DOI: 10.1159/000445586 } 2016 \text { The Author(s). Published by S. Karger AG, Basel } \\ & \text { www.karger.com/cpb }\end{aligned}$ \\ Liu et al.: Possible Mechanisms of HBO Intervention Brain Injury}

Fig. 6C), but the 2.8 ATA HBO administration group could not suppress the number of positive cells obviously more than the SAH + 2.0 ATA HBO group ( $>$ > 0.05, Fig. 6C).

\section{Discussion}

The results of our study provided convincing evidences that HBO administration following SAH could exert a neuroprotective effect by mitigating inflammation, which significantly attenuated EBI (including brain edema, neurological deficit and BBB disruption) in rats. What's more, we found that the potential mechanism responsible for the effect was associated with the inhibition of TLR4/NF- $\kappa$ B signaling pathway and consequent suppression of pro-inflammatory cytokine levels.

The treatment of SAH is always a major challenge for neurologists due to high mortality and morbidity in patients $[2,28]$. Recently, increasing data indicate that EBI rather than vasospasm may be the main cause of poor outcomes in patients with SAH, so treatment of EBI is considered a major goal for improving outcomes of patients $[7,8]$, but the exact molecular mechanisms of EBI have not yet been fully clarified. Accumulating evidences suggest that inflammation and immunity mechanisms play a critical role in regulating the pathogenesis of EBI [7, 29]. With the rapid rise of intracranial pressure and the reduction in cerebral perfusion pressure after $\mathrm{SAH}$, BBB permeability is increased and peripheral immune cells infiltrate into the brain, leading to the production of a great number of inflammatory cytokines and chemokines, which induce brain edema and neuronal injury. Previous studies showed that TLR4/NF- $\kappa$ B signaling pathway is involved in EBI following SAH and becomes an important therapeutic target of SAH $[12,14-16]$.

Through recognizing a wide variety of pathogen associated molecules, the family of TLRs plays a key role in mediating innate immunity response [9]. A variety of TLRs have been identified in human cells. Among the TLR family, TLR4 is expressed in various cell types in the central nervous system (CNS) and mediated intracellular signaling pathways to activate NF- $\kappa$ B, which initiates transcription of genes associated with innate immune responses and inflammation [30]. The expression of NF- $\mathrm{B}$ regulates the transcription of a series of cytokine [31], such as TNF- $\alpha$, IL-6, IL-1 $\beta$ and ICAM-1, and these cytokines released after SAH not only enhance vascular permeability through BBB disruption but also exacerbate cerebral edema and inflammatory to further induce poor neurological grade on pathogenesis of EBI $[12,15]$. Buchanan et al. reported that TLR4 is expressed in various cell types in the CNS, including microglia cells, astrocytes, neurons, and cerebral vascular cells [10]. It has also been reported that tamoxifen, apigenin, melatonin and ursolic acid have neuroprotective effects in EBI following SAH by inhibiting TLR4/NF- $\mathrm{B}$ signaling pathway, which indicated that TLR4/NF- $\mathrm{B}$ pathway is involved in EBI following SAH [15, 16, 32, 33]. In Ma et al.'s study, there is a biphasic change in TLR4 expression in both mRNA and protein: an initial peak (2-6 hours) and a sustained elevation (12-48 hours) in rats after SAH [12]. Consistent with previous studies, our data also suggest that experimental SAH induces significant up-regulation of TLR4 expression and NF- $\kappa$ B regulated pro-inflammatory cytokines (TNF- $\alpha$, IL-1 $\beta$ and IL-6) in EBI, and the inducible expression of TLR4like immunoreactions was predominantly showed in neurons and vascular endothelial cells after SAH by immunohistochemical staining. Furthermore, our data suggests that the elevation of TLR4/NF- $\mathrm{B}$ signaling expression in the cortical may be important in inducing the inflammation and could ultimately aggravate the EBI after SAH.

In recent years, HBO therapy has gained increased attention in reducing the inflammatory response in different research fields. Results of Tan et al. demonstrated that HBO can inhibit the activity of inflammatory cells in the peripheral blood and decrease the levels of inflammatory cytokines (including TNF- $\alpha$, IL-6, IL-8, and IL-10) after SCI [23]. Previous study has shown that the mechanism of HBO to alleviate inflammation in middle cerebral artery occlusion model may be through inhibiting the activated inflammation (IL-1 $\beta$, TNF- $\alpha$, and MPO) and oxidative stress (increased brain levels of ROS, lipid peroxidation and enzymatic pro-oxidants) [18]. In inflammatory pathology of Crohn's disease, hyperbaric oxygen therapy is associated with decreased inflammatory mediators such as TNF- $\alpha$, IL-1 and IL-6 [34]. Recent reports showed 


\section{Cellular Physiology Cell Physiol Biochem 2016;38:2323-2336 \begin{tabular}{c|c|c|} 
DOI: 10.1159/000445586 & $\begin{array}{l}\text { O 2016 The Author(s). Published by S. Karger AG, Basel } \\
\text { www.karger.com/cpb }\end{array}$
\end{tabular} \\ Liu et al.: Possible Mechanisms of HBO Intervention Brain Injury}

that HBO could exert anti-inflammatory effect via inhibiting NF- $\kappa$ B signaling pathway in several disease models $[22,24]$. Therefore, we hypothesize that the neuroprotective effect of HBO in EBI after SAH is closely related to its anti-inflammatory effect via the suppression of TLR4/NF- $\kappa$ B signaling pathway. But until now, there are no studies about it.

It is well-established that HBO could alleviate brain injury following SAH partly by reducing cerebral vasospasm [21], however, in the present study we demonstrated that HBO treatment could ameliorate EBI after SAH via suppressing the activation of TLR4 and NF- $\kappa$ B, along with a downregulation of inflammatory mediators in cortical, and these effects were associated with alleviation of BBB permeability, brain edema and neurological deficit compared to injured animals that did not receive treatment. Our data are in line with previous researches studying the antiinflammatory effects of HBO in other models regarding inflammation [22-24]. These findings suggested that the anti-inflammatory property of $\mathrm{HBO}$ was involved in the beneficial effects in experimental SAH. Though in the dosage of 2.8ATA HBO, BBB permeability could be evidently alleviated more than those in the 2.0ATA HBO group ( $\mathrm{P}<0.05), 2.8 \mathrm{ATA}$ HBO administration could not significantly reduce brain water content and neurological deficit by comparison with 2.0ATA HBO administration $(\mathrm{P}>0.05)$. Although high dose of HBO (2.8ATA) also had led to amelioration in the up-regulation of TLR-4, NF- $\kappa$ B and pro-inflammatory cytokines of TNF- $\alpha$, IL-1 $\beta$ and IL- 6 , there was no statistical difference in measured parameters between the 2.0 ATA and 2.8ATA HBO groups $(\mathrm{P}>0.05)$. On the other hand, we also found that $\mathrm{HBO}$ decreased the protein expression of ICAM-1 following SAH, which was closely related to leukocyte migration and further aggravated cerebral inflammation [35].

In rats treated with $\mathrm{HBO}$ after SAH, the downregulation of TLR4, NF- $\mathrm{K}$, and proinflammatory cytokines corresponded to lower behavior scores compared to injured animals that did not receive treatment, which exhibited reduced inflammatory responses. Moreover, BBB permeability and brain edema were also improved in rats exposed to HBO. Thus, the suppression of inflammation and cytokines induced by HBO treatment resulted in less damage to the brain tissue.

However, there are several limitations to our study. Firstly, according to previous studies, animals received five sessions of HBO treatment in total, but there is no established course of treatment suitable for rats of prechiasmatic injection model, and the difference of repeated HBO sessions could bring inconsistent results, and the ideal time window of $\mathrm{HBO}$ for SAH still should be further studied. Secondly, the authors adopted different dose of HBO (100\% 02, 2.0 ATA or 2.8 ATA) in this experiment, treatment at 2.8 ATA could not significantly inhibit TLR4/NF- $\kappa$ B signaling pathway and consequent expression of pro-inflammatory cytokine compared with 2.0ATA. Hence, the effect of HBO on the inflammatory after SAH needs to be further investigated with different levels of hyperbaria in our future studies. Thirdly, HBO has the properties of antioxidant, anti-inflammatory and anti-apoptosis in the brain tissue after SAH, whether or not the improvement of EBI after SAH could be explained partly by beneficial effects through suppressing TLR4/NF- $\kappa$ B inflammatory signaling pathway remains to be discussed. Finally, the exact molecular mechanisms and signaling pathway of HBO remain elusive, future studies exploring the detailed mechanisms of HBO should be initiated.

Nevertheless, in this study, we found that HBO exerts neuroprotective effects against EBI after SAH by inhibiting the TLR4/NF- $\kappa$ B inflammatory signaling pathway, and 2.8ATA HBO administration could exert evident effect in protecting the integrity of BBB compared with 2.0ATA HBO in EBI after SAH.

\section{Acknowledgements}

This work was supported by the National Natural Science Foundation of China (Grant No. 81400976). 


\section{Cellular Physiology Cell Physiol Biochem 2016;38:2323-2336

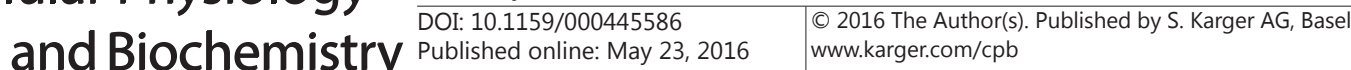

Liu et al.: Possible Mechanisms of HBO Intervention Brain Injury

\section{Disclosure Statement}

None.

\section{References}

1 Bederson JB, Connolly EJ, Batjer HH, Dacey RG, Dion JE, Diringer MN, Duldner JJ, Harbaugh RE, Patel $\mathrm{AB}$, Rosenwasser RH: Guidelines for the management of aneurysmal subarachnoid hemorrhage: A statement for healthcare professionals from a special writing group of the Stroke Council, American Heart Association. Stroke 2009;40:994-1025.

2 Sehba FA, Pluta RM, Zhang JH: Metamorphosis of subarachnoid hemorrhage research: From delayed vasospasm to early brain injury. Mol Neurobiol 2011;43:27-40.

3 Macdonald RL, Kassell NF, Mayer S, Ruefenacht D, Schmiedek P, Weidauer S, Frey A, Roux S, Pasqualin A: Clazosentan to overcome neurological ischemia and infarction occurring after subarachnoid hemorrhage (CONSCIOUS-1): Randomized, double-blind, placebo-controlled phase 2 dose-finding trial. Stroke 2008;39:3015-3021.

4 Vajkoczy P, Meyer B, Weidauer S, Raabe A, Thome C, Ringel F, Breu V, Schmiedek P: Clazosentan (AXV034343), a selective endothelin a receptor antagonist, in the prevention of cerebral vasospasm following severe aneurysmal subarachnoid hemorrhage: Results of a randomized, double-blind, placebo-controlled, multicenter phase IIa study. J Neurosurg 2005;103:9-17.

5 Sozen T, Tsuchiyama R, Hasegawa Y, Suzuki H, Jadhav V, Nishizawa S, Zhang JH: Immunological response in early brain injury after SAH. Acta Neurochir Suppl 2011;110:57-61.

6 Prunell GF, Svendgaard NA, Alkass K, Mathiesen T: Inflammation in the brain after experimental subarachnoid hemorrhage. Neurosurgery 2005;56:1082-1092, discussion 1082-1092.

7 Cahill J, Calvert JW, Zhang JH: Mechanisms of early brain injury after subarachnoid hemorrhage. J Cereb Blood Flow Metab 2006;26:1341-1353.

8 Sehba FA, Hou J, Pluta RM, Zhang JH: The importance of early brain injury after subarachnoid hemorrhage. Prog Neurobiol 2012;97:14-37.

9 Akira S, Takeda K, Kaisho T: Toll-like receptors: Critical proteins linking innate and acquired immunity. Nat Immunol 2001;2:675-680.

10 Buchanan MM, Hutchinson M, Watkins LR, Yin H: Toll-like receptor 4 in CNS pathologies. J Neurochem 2010;114:13-27.

11 Lee SJ, Lee S: Toll-like receptors and inflammation in the CNS. Curr Drug Targets Inflamm Allergy 2002;1:181-191.

12 Ma CX, Yin WN, Cai BW, Wu J, Wang JY, He M, Sun H, Ding JL, You C: Toll-like receptor 4/nuclear factor-kappa B signaling detected in brain after early subarachnoid hemorrhage. Chin Med J (Engl) 2009;122:1575-1581.

13 You WC, Wang CX, Pan YX, Zhang X, Zhou XM, Zhang XS, Shi JX, Zhou ML: Activation of nuclear factorkappaB in the brain after experimental subarachnoid hemorrhage and its potential role in delayed brain injury. PLoS One 2013;8:e60290.

14 Wang CX, Xie GB, Zhou CH, Zhang XS, Li T, Xu JG, Li N, Ding K, Hang CH, Shi JX, Zhou ML: Baincalein alleviates early brain injury after experimental subarachnoid hemorrhage in rats: Possible involvement of TLR4/NF-kappaB-mediated inflammatory pathway. Brain Res 2015;1594:245-255.

15 Zhang T, Su J, Guo B, Wang K, Li X, Liang G: Apigenin protects blood-brain barrier and ameliorates early brain injury by inhibiting TLR4-mediated inflammatory pathway in subarachnoid hemorrhage rats. Int Immunopharmacol 2015;28:79-87.

16 Sun X, Ji C, Hu T, Wang Z, Chen G: Tamoxifen as an effective neuroprotectant against early brain injury and learning deficits induced by subarachnoid hemorrhage: Possible involvement of inflammatory signaling. J Neuroinflammation 2013;10:157.

17 Weaver LK, Hopkins RO, Chan KJ, Churchill S, Elliott CG, Clemmer TP, Orme JJ, Thomas FO, Morris AH: Hyperbaric oxygen for acute carbon monoxide poisoning. N Engl J Med 2002;347:1057-1067.

18 Matchett GA, Martin RD, Zhang JH: Hyperbaric oxygen therapy and cerebral ischemia: Neuroprotective mechanisms. Neurol Res 2009;31:114-121. 


\section{Cellular Physiology Cell Physiol Biochem 2016;38:2323-2336 \begin{tabular}{l|l} 
and Biochemistry Published online: May 23, 2016 & $\begin{array}{l}\text { D) } 2016 \text { The Author(s). Published by S. Karger AG, Basel } \\
\text { www.karger.com/cpb }\end{array}$ \\
\hline
\end{tabular}}

Liu et al.: Possible Mechanisms of HBO Intervention Brain Injury

19 Bennett MH, Mitchell SJ, Young D, King D: The use of deep tables in the treatment of decompression illness: The Hyperbaric Technicians and Nurses Association 2011 Workshop. Diving Hyperb Med 2012;42:171180.

20 Ostrowski RP, Colohan AR, Zhang JH: Mechanisms of hyperbaric oxygen-induced neuroprotection in a rat model of subarachnoid hemorrhage. J Cereb Blood Flow Metab 2005;25:554-571.

21 Ostrowski RP, Zhang JH: Hyperbaric oxygen for cerebral vasospasm and brain injury following subarachnoid hemorrhage. Transl Stroke Res 2011;2:316-327.

22 Kang N, Hai Y, Yang J, Liang F, Gao CJ: Hyperbaric oxygen intervention reduces secondary spinal cord injury in rats via regulation of HMGB1/TLR4/NF-kappaB signaling pathway. Int J Clin Exp Pathol 2015;8:11411153.

23 Tan J, Zhang F, Liang F, Wang Y, Li Z, Yang J, Liu X: Protective effects of hyperbaric oxygen treatment against spinal cord injury in rats via toll-like receptor 2/nuclear factor-kappaB signaling. Int J Clin Exp Pathol 2014;7:1911-1919.

24 Rinaldi B, Cuzzocrea S, Donniacuo M, Capuano A, Di Palma D, Imperatore F, Mazzon E, Di Paola R, Sodano L, Rossi F: Hyperbaric oxygen therapy reduces the toll-like receptor signaling pathway in multiple organ failures. Intensive Care Med 2011;37:1110-1119.

25 Jeon H, Ai J, Sabri M, Tariq A, Macdonald RL: Learning deficits after experimental subarachnoid hemorrhage in rats. Neuroscience 2010;169:1805-1814.

26 Sugawara T, Ayer R, Jadhav V, Zhang JH: A new grading system evaluating bleeding scale in filament perforation subarachnoid hemorrhage rat model. J Neurosci Methods 2008;167:327-334.

27 Zhang XS, Zhang X, Wu Q, Li W, Wang CX, Xie GB, Zhou XM, Shi JX, Zhou ML: Astaxanthin offers neuroprotection and reduces neuroinflammation in experimental subarachnoid hemorrhage. J Surg Res 2014;192:206-213.

28 Chen S, Luo M, Zhao Y, Zhang Y, He M, Cai W, Liu A: Fasudil stimulates neurite outgrowth and promotes differentiation in c17.2 neural stem cells by modulating notch signalling but not autophagy. Cell Physiol Biochem 2015;36:531-541.

29 Kooijman E, Nijboer CH, van Velthoven CT, Kavelaars A, Kesecioglu J, Heijnen CJ: The rodent endovascular puncture model of subarachnoid hemorrhage: Mechanisms of brain damage and therapeutic strategies. J Neuroinflammation 2014;11:2.

30 Anderson KV: Toll signaling pathways in the innate immune response. Curr Opin Immunol 2000;12:13-19.

31 Xu RX, Liu RY, Wu CM, Zhao YS, Li Y, Yao YQ Xu YH: DNA damage-induced NF-kappaB activation in human glioblastoma cells promotes miR-181b expression and cell proliferation. Cell Physiol Biochem 2015;35:913-925.

32 Wang Z, Wu L, You W, Ji C, Chen G: Melatonin alleviates secondary brain damage and neurobehavioral dysfunction after experimental subarachnoid hemorrhage: Possible involvement of TLR4-mediated inflammatory pathway. J Pineal Res 2013;55:399-408.

33 Zhang T, Su J, Guo B, Zhu T, Wang K, Li X: Ursolic acid alleviates early brain injury after experimental subarachnoid hemorrhage by suppressing TLR4-mediated inflammatory pathway. Int Immunopharmacol 2014;23:585-591.

34 Weisz G, Lavy A, Adir Y, Melamed Y, Rubin D, Eidelman S, Pollack S: Modification of in vivo and in vitro TNFalpha, IL-1, and IL-6 secretion by circulating monocytes during hyperbaric oxygen treatment in patients with perianal Crohn's disease. J Clin Immunol 1997;17:154-159.

35 Xie X, Wu X, Cui J, Li H, Yan X: Increase ICAM-1 and LFA-1 expression by cerebrospinal fluid of subarachnoid hemorrhage patients: Involvement of TNF-alpha. Brain Res 2013;1512:89-96. 